\title{
The Reasons for the Income Gap between Urban and Rural Residents in China
}

\author{
Zhao Sudan \\ Department of Economics \\ Sichuan University, SCU \\ Chengdu, China \\ Sudan630@163.com
}

\begin{abstract}
With the rapid growth of the economy, China's urban and rural income gap showed a rising trend since 1978. Based on the empirical data of China from 2005 to 2014, this paper will study the dynamic relationship and mechanism between the income structure and the income gap between urban and rural areas from the perspective of proportion. The results show that the wage income is the strongest factor in the expansion of the income gap, the second is the transfer income, and the property income is the weakest, while the operating income is the only income to narrow the income gap.
\end{abstract}

Keywords-Income Structure, Urban and Rural Income Gap, Income Gap Coefficient, Empirical Data

\section{INTRODUCTION}

With the rapid growth of the economy, China's urban and rural income gap showed a rising trend since 1978. In recent years, many domestic and foreign scholars have analyzed and studied the income gap between urban and rural areas from the perspective of income structure. Through the empirical analysis, Lin Boqiang (2013) ${ }^{[2]}$, Chen Lizhong and Zhang Jianhua (2014) ${ }^{[3]}$, Fan Conglai and Zhang Zhongjin (2011) ${ }^{[4]}$, Huang Zuhui and Lu Jianqin (2005) ${ }^{[5]}$, Yang Canming and Guo Huifang (2007) ${ }^{[6]}$ point out that the wage income tend to expand the income gap between urban and rural areas, operating income plays a role in narrowing the urban-rural income gap, and the country the introduction policies to increase the proportion of the transfer income is increased by country policies, thereby it reduces the income gap to a certain extent.

The past papers mostly use the Gini coefficient, GE index or Theil index to decompose the income, while the dynamic relationship between the peasants' income structure and the income gap is lack of consideration, and few articles have explained the interactive relationship between the two. Considering this, this paper will be based on the past research, and start from the peasants' income structure, using empirical data from 2005 to 2014 , to explore the dynamic relation and influence between peasants' income structure and the income gap between urban and rural areas.

\section{THE INCOME OF URBAN AND RURAL RESIDENTS AND THE MEASUREMENT METHOD OF THE GAP EFFECT COEFFICIENT}

At present, the income sources of both urban residents and rural residents generally include the following four parts: wage income, operating income, transfer income and property income. In order to measure the impact of each sub income on the income gap between urban and rural residents, this paper introduces the relative income gap coefficient $(\mathrm{G})$ to measure the income gap between urban and rural residents:

$$
G=(\mathrm{Iu}-\mathrm{Ir}) / \sqrt{\mathrm{Iu} \times \mathrm{Ir}}
$$

Among them, $\mathrm{u}$ represents for urban residents, $\mathrm{R}$ represents for rural residents, Iu and Ir represents for the disposable income of urban residents per capita and the disposable income of rural residents per capita. If formula of the relative income gap coefficient $(G)$ of urban and rural residents' overall income is derived, the formula can be obtained:

$$
\begin{gathered}
G=\frac{I u-I r}{\sqrt{I u \times I r}}=\frac{\sum_{i=1}^{n} I u i-\sum_{i=1}^{n} I r i}{\sqrt{I u \times I r}}=\sum_{i=1}^{n} \frac{I u i-I r i}{\sqrt{I u \times I r}}= \\
\sum_{i=1}^{n} \frac{I u i-I r i}{\sqrt{I u i \times I r i}} \times \sqrt{\frac{I u i}{I u}} \times \sqrt{\frac{I r i}{I r}}=\sum_{i=1}^{n} g i \times \sqrt{u i} \times \sqrt{r i}
\end{gathered}
$$

In the formula (2), I represents the i revenue, $i=1,2,3, \ldots, n$, $\mathrm{g}_{\mathrm{i}}$ is for the relative gap coefficient of item $\mathrm{i}, \mathrm{g}_{\mathrm{i}}=\left(\mathrm{I}_{\mathrm{ui}}-\mathrm{I}_{\mathrm{ri}}\right) /\left(\mathrm{I}_{\mathrm{ui}}\right.$ $\left.\times I_{\mathrm{ri}}\right)^{1 / 2}$, which represents the income gap of each sub income; $\mathrm{u}_{\mathrm{i}}$ represents $\mathrm{i}$ income in the proportion of urban residents' disposable income, $\mathrm{u}_{\mathrm{i}}=\mathrm{I}_{\mathrm{ui}} / \mathrm{I}_{\mathrm{u}}$, wherein, $\mathrm{I}_{\mathrm{ui}}$ represents the average of $\mathrm{i}$ income of urban residents, $\sum_{i=1}^{n} r i=1, \mathrm{u}_{\mathrm{i}}$ reflects the income structure of urban residents; $r_{i}$ is for $i$ income in the proportion of rural residents' disposable income, $r_{i}=I_{r i} / I_{r}$, wherein, $I_{r i}$ represents average of $i$ income of rural residents, $\sum_{i=1}^{n} r i=1, \mathrm{r}_{i}$ reflects the income structure of rural residents.

To investigate the contribution of each sub income to the overall income gap between urban and rural residents, we also need to examine the effect coefficient. In this paper, we use $C_{i}$ to represent the effect coefficient of urban and rural residents on the overall income gaps:

$$
C i=\frac{g i \times \sqrt{u i} \times \sqrt{r i}}{G}=\frac{g i}{G} \times \sqrt{u i} \times \sqrt{r i}
$$

III. THE EFFECT COEFFICIENT OF DIFFERENT INCOME SOURCES ON THE INCOME GAP BETWEEN URBAN AND RURAL RESIDENTS

According to the urban and rural residents' specific sources of income from 2005 to 2014 in China, we can use these data to estimate the influence of the four sources of income on the 
income gap respectively, and to measure their change and the effect coefficient of the overall gap between urban and rural residents.

\section{A. Wage Income}

As can be seen from table 1, the impact of wage income gap on the overall income gap has two main characteristics. On the one hand, the wage income of urban and rural residents contributes mostly to expand the overall income gap, the average annual value is up to $84.29 \%$. From the relative inequality coefficient of urban and rural residents' wage income, the average value of GI is 1.94. From the ratio of absolute income of urban and rural residents, the highest ratio is 6.64, with an average annual value of up to 5.63. Thus, the wage income gap has led to a serious imbalance in the income structure, becoming the main reason for the income gap between urban and rural areas.

TABLE I. THE EFFECT OF WAGE INCOME ON INCOME INEQUALITY

\begin{tabular}{|c|c|c|c|c|c|}
\hline Year & $\mathrm{g}_{\mathrm{i}}$ & $\mathrm{g}_{\mathrm{i}} / \mathrm{G}$ & $\mathrm{u}_{\mathrm{i}}(\%)$ & $\mathrm{r}_{\mathrm{i}}(\%)$ & $\mathrm{C}_{\mathrm{i}}(\%)$ \\
\hline 2005 & 2.19 & 1.77 & 74.31 & 36.08 & 91.5 \\
\hline 2006 & 2.13 & 1.69 & 74.55 & 38.33 & 90.45 \\
\hline 2007 & 2.14 & 1.67 & 74.24 & 38.55 & 89.56 \\
\hline 2008 & 2.06 & 1.62 & 71.6 & 38.94 & 85.71 \\
\hline 2009 & 2.04 & 1.6 & 72.1 & 40 & 85.85 \\
\hline 2010 & 1.95 & 1.58 & 71.73 & 41.07 & 85.49 \\
\hline 2011 & 1.84 & 1.53 & 70.67 & 42.47 & 83.93 \\
\hline 2012 & 1.8 & 1.5 & 70.57 & 43.55 & 83.42 \\
\hline 2013 & 1.6 & 1.48 & 61.05 & 39.59 & 72.96 \\
\hline 2014 & 1.66 & 1.51 & 61.65 & 38.73 & 73.98 \\
\hline Mean Value & 1.94 & 1.6 & 70.25 & 39.73 & 84.29 \\
\hline
\end{tabular}

On the other hand, from the time sequence, the wage income gap between urban and rural income gap continues to decline. The effect coefficient of wage income gap (Ci) showed a sustained decline, from $91.5 \%$ in 2005 to $61.65 \%$ in 2014 . The main reason is that the proportion of wage income of urban residents is relatively decreased, while the proportion of rural residents' wage income is rising. This not only increases the average level of wage income between urban residents and rural residents, but also optimizes the income structure of urban residents and rural residents, weakening the wage income gap effect.

\section{B. Operating Income}

As can be seen from table 2, the operating income gap has a negative effect on the overall income gap, which indicates that it can narrow the income gap between urban and rural areas. Secondly, the operating income gap between urban and rural residents is still large. Seeing from the urban and rural residents' operating income relative gap coefficient, $\mathrm{g}_{\mathrm{i}}$ is always negative, with an average annual value of about -0.56 . Seeing from the absolute ratio of urban and rural residents' operating income, the highest ratio is 2.71 , and the average annual value is 1.32 . Therefore, the operating income gap can bridge the income structure imbalance, restricting the widening income gap between urban and rural areas
TABLE II. THE EFFECT OF OPERATING INCOME ON INCOME INEQUALITY

\begin{tabular}{|c|c|c|c|c|c|}
\hline Year & gi & gi/G & ui (\%) & ri(\%) & $\mathrm{Ci}(\%)$ \\
\hline 2005 & -1.04 & -0.84 & 6.48 & 56.67 & -16.09 \\
\hline 2006 & -0.9 & -0.71 & 6.88 & 53.83 & -13.72 \\
\hline 2007 & -0.87 & -0.68 & 6.82 & 52.98 & -12.99 \\
\hline 2008 & -0.52 & -0.41 & 9.21 & 51.16 & -8.91 \\
\hline 2009 & -0.51 & -0.4 & 8.9 & 49.03 & -8.3 \\
\hline 2010 & -0.51 & -0.41 & 8.97 & 47.86 & -8.49 \\
\hline 2011 & -0.38 & -0.32 & 10.13 & 46.18 & -6.82 \\
\hline 2012 & -0.33 & -0.27 & 10.37 & 44.63 & -5.92 \\
\hline 2013 & -0.26 & -0.24 & 11.16 & 40.4 & -5.07 \\
\hline 2014 & -0.28 & -0.26 & 11.04 & 41.73 & -5.47 \\
\hline Mean Value & -0.56 & -0.45 & 9 & 48.45 & -9.18 \\
\hline
\end{tabular}

From the time sequence, the weakening effect of the operating income is gradually declining, and the restricting effect of widening the income gap between urban and rural areas is decreasing year by year. The effect coefficient of operating income decreased from $16.09 \%$ in 2005 to $5.47 \%$ in 2014; at the same time, the relative gap coefficient of the operating income increased to -0.28 from -1.04 . The main reason lies in the acceleration of the growth of urban residents' operating income and the slow increase of operating income of rural residents. Even so, the operating income is the main source of income of rural residents, it also has gradually become an important source of urban residents' income; it is still the main source of the weakening effect of narrowing the urban-rural income gap and income distribution optimization.

\section{Transfer Income}

Table 3 shows that in the four the income we discussed, transfer income gap between urban and rural residents is the largest. In the given years, relative inequality coefficient of urban and rural residents' transfer income is as high as 2.83 . In 2005 , the income of urban residents was 17.98 times higher than that of rural residents. In the year of 2012, the number was 9.23, which was much higher than the wage income gap between urban and rural residents. This is mainly caused by the unequal or discriminatory income redistribution system, mainly reflected in the urban and rural division of the transfer of income policy. The effect coefficient of transfer income inequality on urban and rural residents' total income inequality is large, the maximum value is $34.59 \%$, and the average annual value is up to $30.24 \%$. Just because the transfer income in the proportion of the total income of urban and rural residents was less than that of wage income, transfer income accounted $25.92 \%$ and $8.67 \%$ for the average value of urban residents' and rural residents' total income, thus its contribution to the overall income gap rate is not as big as wage income's contribution.

TABLE III. THE EFFECT OF TRANSFER INCOME ON INCOME INEQUALITY

\begin{tabular}{|c|c|c|c|c|c|}
\hline Year & gi & gi/G & ui(\%) & ri(\%) & Ci(\%) \\
\hline 2005 & 4 & 3.23 & 25.26 & 4.53 & 34.59 \\
\hline 2006 & 3.75 & 2.98 & 24.65 & 5.04 & 33.26 \\
\hline 2007 & 3.65 & 2.86 & 24.55 & 5.37 & 32.79 \\
\hline 2008 & 3.2 & 2.52 & 24.89 & 6.79 & 32.71 \\
\hline 2009 & 3.07 & 2.4 & 26.29 & 7.72 & 34.25 \\
\hline 2010 & 3.05 & 2.46 & 26.65 & 7.65 & 35.17 \\
\hline 2011 & 2.87 & 2.39 & 26.17 & 8.07 & 34.69 \\
\hline 2012 & 2.72 & 2.28 & 25.92 & 8.67 & 34.13 \\
\hline 2013 & 0.98 & 0.91 & 16.39 & 17.9 & 15.56 \\
\hline 2014 & 1 & 0.91 & 16.04 & 17.47 & 15.27 \\
\hline Mean Value & 2.83 & 2.29 & 23.68 & 8.92 & 30.24 \\
\hline
\end{tabular}


From the time sequence, the transfer income inequality effect coefficient showed a gradual decline trend. During the period of 2005-2009, the policy effect of the transfer payment system between urban and rural areas is more obvious, the relative inequality coefficient of transfer income is declining year by year, and the income inequality effect of transfer income is decreasing year by year. The reason is that with the implementation of the minimum living security system in rural areas and the gradual establishment of the rural social security system, governments at all levels have increased the intensity of the transfer payments to rural residents. After 2009, the inequality effect coefficient of transfer income fluctuates, which may be caused by a series of measures implemented after the financial crisis. In 2013 and 2014, the transfer income inequality effect coefficient decreased greatly, probably because since 2013, the National Bureau of statistics carry out the household incomes and living conditions survey under the integration of urban and rural, differing from the survey in which urban and rural household was separated before 2013 . After that, the survey scope, survey methods and survey indexes are all different. In general, the transfer of urban and rural residents income gap is still large, and is still a significant factor to strengthen the effect of the total urban and rural residents' income inequality and worsen the income structure of urban and rural residents.

\section{Property Income}

It can be seen from table 4 that the effect of property income inequality on the gross income inequality between urban and rural residents is still relatively weak, the maximum effect coefficient is only 3.34, and its annual mean is about 1.45. To be sure, on the one hand, with the development of market economy and residential property accumulation growth, the income of whether urban or rural residents in the proportion of the overall income will continue to rise, on the other hand, because the property income has obvious accumulating effect and strong "Matthew effect", property income gap between urban and rural areas in the future may expand at a faster rate, therefore, in the long run, the role of property income to the overall income gap between urban and rural residents will increase.

TABLE IV. THE EFFECT OF PROPERTY INCOME ON INCOME INEQUALITY

\begin{tabular}{|c|c|c|c|c|c|}
\hline Year & gi & gi/G & ui (\%) & ri (\%) & $\mathrm{Ci}(\%)$ \\
\hline 2005 & 0.8 & 0.65 & 1.84 & 2.72 & 1.44 \\
\hline 2006 & 0.92 & 0.73 & 2.07 & 2.8 & 1.76 \\
\hline 2007 & 1.04 & 0.82 & 2.53 & 3.1 & 2.28 \\
\hline 2008 & 1 & 0.78 & 2.45 & 3.11 & 2.17 \\
\hline 2009 & 0.98 & 0.77 & 2.51 & 3.24 & 2.2 \\
\hline 2010 & 0.98 & 0.79 & 2.72 & 3.42 & 2.41 \\
\hline 2011 & 1.09 & 0.91 & 2.98 & 3.28 & 2.83 \\
\hline 2012 & 1.09 & 0.91 & 2.88 & 3.15 & 2.75 \\
\hline 2013 & 3.28 & 3.05 & 9.57 & 2.12 & 13.71 \\
\hline 2014 & 3.34 & 3.04 & 9.47 & 2.06 & 13.45 \\
\hline Mean Value & 1.45 & 1.24 & 3.9 & 2.9 & 4.5 \\
\hline
\end{tabular}

\section{COMPARATIVE ANALYSIS OF THE EFFECT OF SUB INCOME}

The unequal effect of each sub income on the total income inequality has different effects. The inequality effect of wage income and transfer income will significantly increase and expand the aggregate income inequality, the inequality effect of property income will potentially expand the total inequality, and the inequality effect of operating income inequality, income inequality effect can effectively reduce the total income inequality. Accordingly, we should make full use of the differential income inequality effect to reduce the income inequality between urban and rural areas, and realize the optimization of income structure.

There is a large difference in the degree and influence of relative inequality between the sub items, which also differs from the overall trend of the gross income. The inequality coefficient of transfer income is the largest, followed by wage income, property income, and operating income's inequality coefficient is negative. While the equal distribution of wage income and transfer income between urban and rural residents has increased, the degree of equalization of operating income between urban and rural residents has been significantly reduced.

The income structure has a great impact on the income inequality effect and thus has a great impact on the gross income inequality, so we should give full play to the different income inequality effect to optimize the income structure. The wage income inequality is lower than the transfer income, but because of the wage income in the proportion of the total income is more than transfer income, the wage income inequality has significant effects on the total household income inequality. From the operating income gap, if the proportion of the operating income is increased, it will strengthen the inhibitory effect of income inequality, which will not only increases the total income but also optimize the income structure; from the transfer income gap, with the gradual establishment of the social security system for rural residents, the transfer income gap should be reduced in the short term, but its effect is limited; from the property income, the property income gap between urban and rural residents may rapidly expand in the future, it will promote the expansion of the income gap between urban and rural residents.

\section{CONCLUSIONS AND POLICY RECOMMENDATIONS}

In the conclusion of the study, wage income and transfer income increase income inequality, while operating income reduces income inequality. But from the income structure, the strengthening effect of the wage income inequality accounted for the highest and the most significant in total income; transfer income inequality may not be lower than that of wage income, and adjusting its proportion is particularly important; the weakening effect of operating income is severely inhibited because of its low proportion, so its proportion needs to be increased; the strengthening effect of property income is not fully reflected because of its low proportion, and it is necessary to be controlled. Thus, Thus, in order to optimize the income structure through making use of the different effect of sub income, we should maintain the stability of wage income and adjust transfer income, making the proportion more reasonable; take efforts to increase operating income gradually to enhance the weakening effect; and control the potential strengthening effect of property income by making the proportion relatively appropriate. 
According to the above analysis, the author thinks that we should take the following measures to curb the expansion of the income gap between urban and rural residents, one of which is to promote the rural labor transfer to non-agricultural industries, in order to curb the expansion of urban labor and migrant workers wage income gap; the second is to promote the business income growth of rural residents; the third is the establishment of the property tax system; the fourth is to gradually establish the integration of urban and rural social security system.

\section{REFERENCES}

[1] K.A. Rahman, "Income inequality in China:Composition, distribution and of household (1988-1995), "The China Quarterly, 1998, vol. 15, pp. 61-64.
[2] L. Boqiang, "China's economic growth, poverty reduction and policy choice ," Economic Research, 2013, vol. 12, pp. 13-17.

[3] C. Lizhong, Z. Jianhua. "Dynamic relationship among economic growth, income distribution and poverty reduction process: An Empirical Analysis of rural China," Chinese population science, 2014, vol. 1, pp. 23-26.

[4] Z. Zhongjin, J. Gali, "Partial income inequality research,"Financial effect and the income structure,2011, vol. 1, pp. 56-60.

[5] H. Zuhui, L. Jianqin, " Research on the income gap between urban and rural areas: An analysis based on the source of income,"Journal of Zhejiang University, 2005, vol.4, pp. 39-44.

[6] Y. Canming, G. Huifang, and S. Qunli. "Empirical analysis on the composition of China's peasants' income," Finance and Trade Economics,2007, vol.10, pp. 67-72. 